\title{
Murine Gammaherpesvirus (MHV-68) Transforms Cultured Cells in vitro
}

\author{
Veronika Mrázováa Tatiana Betáková $^{b}$ Marcela Kúdelováb \\ Miroslava Šupolíkováa Veronika Lachová ${ }^{b}$ Barbora Lapuníkováa \\ František Golais $^{a}$ \\ a Department of Microbiology and Virology, Faculty of Natural Science, Comenius University, and \\ b Institute of Virology, Slovak Academy of Science, Bratislava, Slovakia
}

\section{Key Words}

MHV-68 - Gammaherpesvirus · Ultraviolet irradiation ·

Transformation in vitro

\begin{abstract}
Human dermal fibroblasts and mouse NIH/3T3 cells acquired the transformed phenotype ('criss-cross' pattern of growth) after infection with ultraviolet-irradiated murine gammaherpesvirus (MuHV-4 strain 68; MHV-68). These cells with changed phenotype could be serially cultured for 5-6 passages (35-40 days), and then they entered into crisis and most of them died. In a small number of cultures, however, foci of newly transformed cells appeared from which two stable cell lines were derived. After 6-9 cell culture passages of the MHV-68 transformed cell lines, MHV-68 DNA and virus antigen could be detected by PCR and immunofluorescence assay along with the disappearance of actin bundles, indicating that both transformed cell lines might be oncogenic.
\end{abstract}

(c) 2015 S. Karger AG, Basel

Murine gammaherpesvirus (MHV-68, MuHV-4) is a member of the Rhadinovirus genus and Gammaherpesvirinae subfamily of the Herpesviridae family. However, as distinct from other members of this subfamily such as Epstein-Barr virus or Kaposi sarcoma-associated virus, MHV-68 infects a wide variety of cell lines, reaching high titers, and forming plaques, and some mice have even developed lymphoproliferative disease and displayed high-grade lymphomas a long time after in vivo infection [1-3]. Besides studies on tumor cell line S11 derived from MHV-68 infected mice growing into tumors in nude mice [4], the transforming ability of MHV-68 has not been demonstrated $[5,6]$ as being distinct from that of some alpha- or betaherpesviruses whose oncogenic potential under various conditions in vitro has been studied over more than two decades [7-10]. Considering the fact that MHV-68, although it is a gammaherpesvirus, in some biological characteristics resembles more alphaherpesviruses, we decided to demonstrate the possible transforming ability of MHV-68 using the same method that was shown to be successful for alphaherpesviruses. We infected human dermal fibroblast (hDF) (ATCC PCS-201-012) and mouse dermal fibroblast NIH/3T3 (ATCC CRL-1658) cells with ultraviolet (UV)-irradiated MHV-68, thus repeating the experiments of Duff and Rapp [8] and Boyd and Orme [7] who demonstrated the development of transformed foci in hamster embryo cells and Swiss/3T3 cells infected with UV-irradiated HSV-2.

\section{KARGER 125}

(c) 2015 S. Karger AG, Base

$0300-5526 / 15 / 0582-0069 \$ 39.50 / 0$

E-Mail karger@karger.com

www.karger.com/int
František Golais

Comenius University, Faculty of Natural Science

Department of Microbiology and Virology

SK-842 15 Bratislava (Slovakia)

E-Mail franz_golais@yahoo.de 


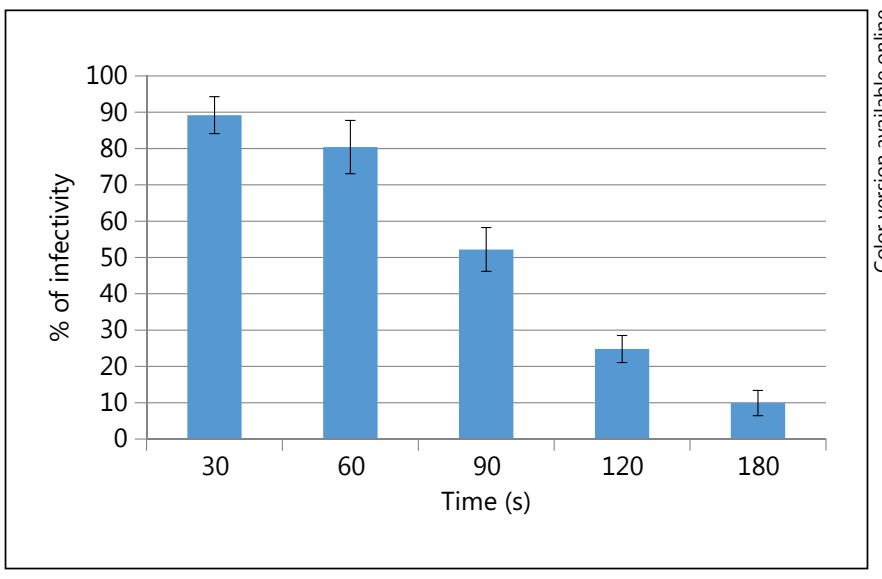

Fig. 1. Inactivation of MHV-68 by UV light.

Two microliters of MHV-68 stock at $0.5 \times 10^{6} \mathrm{PFU} / \mathrm{ml}$ loaded into plastic Petri dishes were exposed to UVB (germicidal lamp) at a distance of $20 \mathrm{~cm}$ with constant rotation. Samples of virus irradiated for 30, 60, 90, 120, 150 , and 180 s were plaque-titrated in BHK-21 cells (fig. 1) and then diluted $10^{-1}$ to $10^{-3}$ times to infect the monolayers of $\mathrm{hDF}$ and $\mathrm{NIH} / 3 \mathrm{~T} 3$ cells grown in 24-well plates along with the same dilutions of nonirradiated virus serving as controls. Some infected cells, especially those infected with irradiated virus diluted $10^{-1}$ times and all controls infected with nonirradiated virus, were destroyed by the cytopathic effect within 3-5 days. However, most cells infected with UV-irradiated virus showed no cytopathic effect, but acquired altered morphology with a multilayered 'criss-cross' pattern of growth (fig. 2a, b). These morphologically altered cells could be passaged 5-6 times for about 35-40 days after which they entered into crisis. Their growth slowed rapidly and they ceased to form a confluent monolayer, detached from the bottom and the cultures were lost. In some cultures, however, small foci of new transformed cells appeared both in hDF and in $\mathrm{NIH} / 3 \mathrm{~T} 3$ cells forming islands of transformed cells, from which new transformed cell lines with stable properties could be derived (fig. 2c). These cells could then be passaged continuously and were used for further studies.

For immunofluorescence studies, the cells were stained with Alexa Fluor 555 Phalloidin (Invitrogen), rabbit hyperimmune anti-MHV-68 serum, and Protein G Alexa Fluor 488 (Invitrogen). Nuclei were labeled with DAPI (Invitrogen). Both human and mouse transformed cell lines contained MHV-68 antigen visible as diffused fluorescence throughout the cytoplasm. Normally developed filamentous actin bundles were observed both in normal
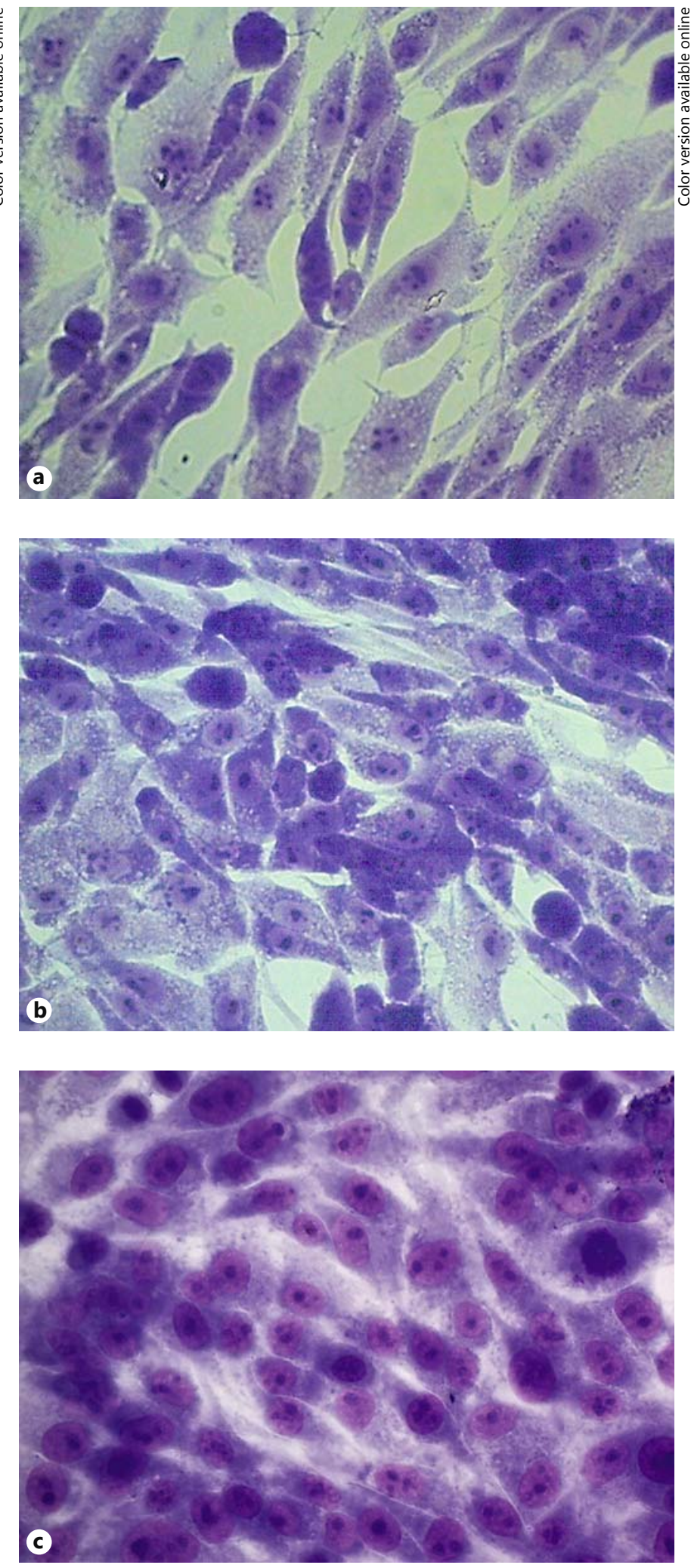

Fig. 2. Control NIH/3T3 cells (a) and NIH/3T3 (b) cells infected with UV-irradiated MHV-68. c Transformed NIH/3T3 cells derived from cells infected with $\mathrm{UV}$-irradiated virus. 

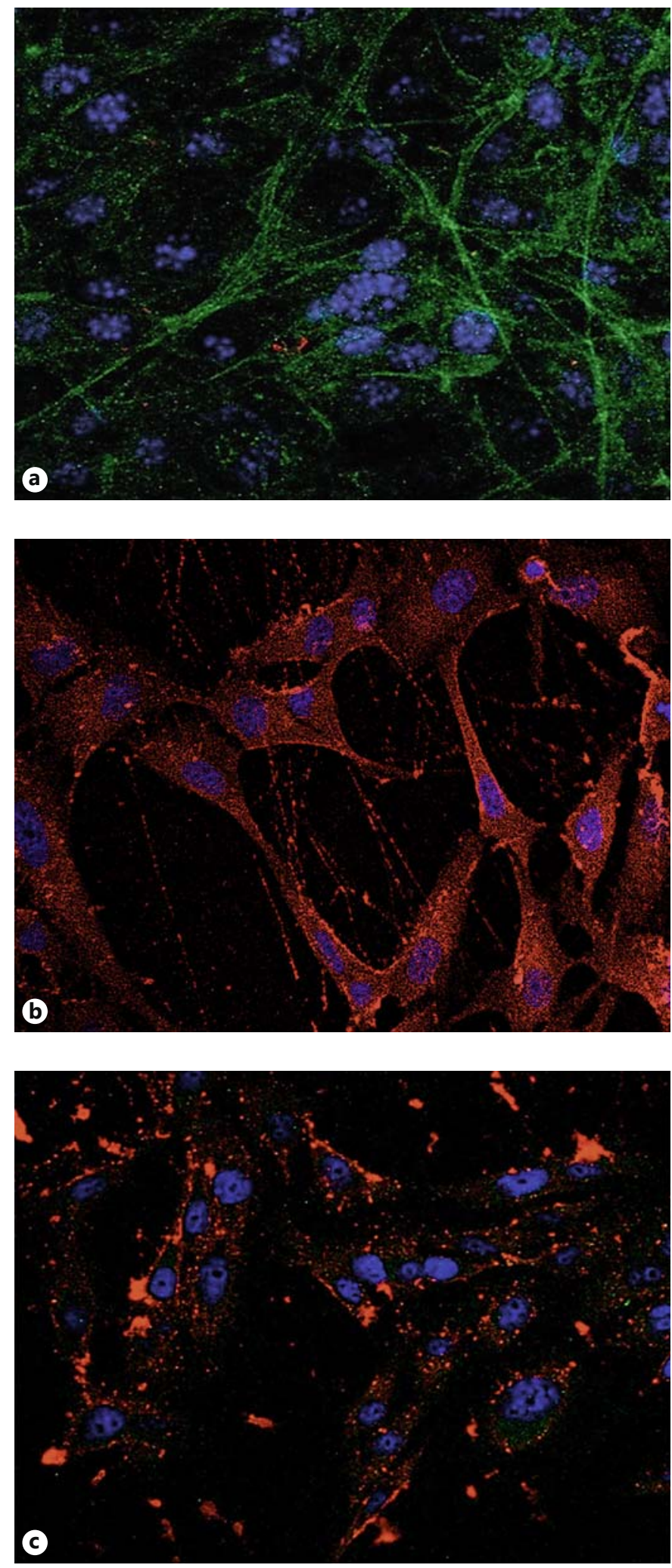

Fig. 3. a Control hDF with stained actin bundles. b Viral antigen in hDF cells transformed by irradiated MHV-68. c Transformed $\mathrm{hDF}$ cells showing viral antigen and the loss of actin bundles.

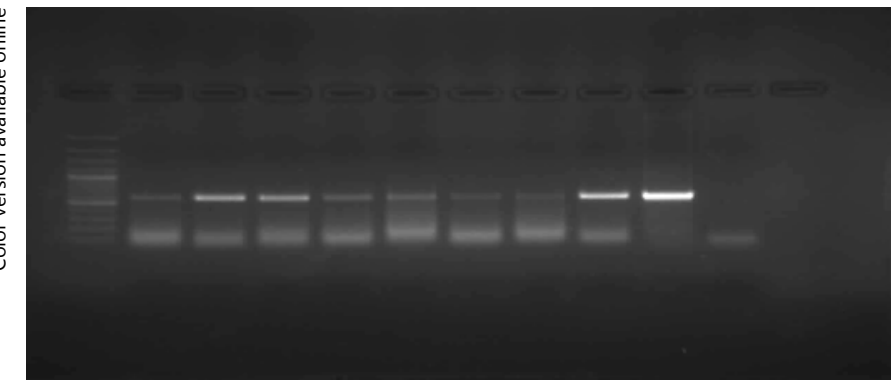

Fig. 4. Detection of MHV-68 DNA in virus-transformed human and mouse dermal fibroblast cell lines by PCR. Lane 1: 100-bp Plus ladder (Fermentas). Lanes 2-4: human cells after 7-9 cell culture passages. Lanes 5-8: NIH/3T3 cells after 6-9 cell culture passages. Lanes 9-10: 20- and 100-ng MHV-68 BAC DNA (positive controls). Lane 11: PCR without template (negative control).

nontransformed hDF and NIH/3T3 cells. Transformation of both cell lines, however, led to the disappearance of actin bundles. Immunofluorescence results are shown in figure 3.

The presence of DNA of MHV-68 was detected after 6-9 cell culture passages of both MHV-68 transformed human and mouse cell lines using PCR. In PCR assays, the ORF50 gene encoding the R transactivator of MHV68 was targeted with primers $5^{\prime}$-AACTGGAACTCTTCT GTGGC- $3^{\prime}$ and $5^{\prime}$-GGCCGCAGACATTTAATGAC-3', by which a 586-bp long product was amplified [11] (fig. 4). Samples that tested positive were reexamined and confirmed (data not shown) using nested PCR specific for the glycoprotein gp 150 gene of MHV-68 (allowing to detect even one copy of virus genome) originally developed to detect MHV-68 in organs of experimentally infected mice and ticks [12]. We employed primer pair gpF7 5'-GAAACAACCACCCCTTCCCAA-3' and gpR 5'-CTGTGGGTGCCCAGCGGAGG-3', which amplified a 1,011-bp long product, and primer pair gpF4 $5^{\prime}$-TCCCAAACAAGAGGATG- ${ }^{\prime}$ and gpR2 $5^{\prime}$-TGCTG GTTGAGTGGTGGT-3', which amplified a 640-bp long product, following the method described in detail by $\mathrm{Fi}$ cová et al. [13].

MHV-68 is able to transform cultured cells in vitro and this transformation is associated with the disappearance of actin bundles. The changes in the cytoskeleton play a critical role in the regulation of various cellular processes linked to transformation, e.g. proliferation, contact inhibition, and anchorage-independent growth. The disappearance of actin bundles is generally considered to be associated with malignancy [14-17], thus both the human and mouse transformed cell lines reported in this 
paper might be oncogenic and similar to those reported for other gammaherpesvirus-transformed cell lines. These appear to be the first findings about the transforming activity of MHV-68 in vitro, and the results might open a new area in MHV-68 research. Further studies will be performed in attempts to characterize these two newly derived transformed cell lines in more detail through analysis of their phenotype and karyotype, anchorage-independent growth, clonability, oncogenicity in vivo, la- tent infection, virus genome integrity, and noninduced and induced production of virus particles by otherwise latently infected cells within the transformed cell lines.

\section{Acknowledgment}

This work was supported by grants APVV-0676-12, APVV0621-12, and VEGA Nos 2/0091/13, 2/0005/12, and 1/0262/13 and ITMS 26240220086

\section{References}

1 Mistríková J, Rašlová $\mathrm{H}, \mathrm{Mrmusová} \mathrm{M,} \mathrm{Kúde-}$ lová M: A murine gammaherpesvirus. Acta Virol 2000;44:211-226.

2 Nash A, Dutia BM, Stewart JP, Davison AJ: Natural history of murine gammaherpesvirus infection. Phil Trans R Soc Lond B 2001;356: 569-579.

-3 Simas JP, Efstathiou S: Murine gammaherpesvirus 68: a model for the study of gammaherpesvirus pathogenesis. Trends Microbiol 1998;6:276-282.

4 Usherwood EJ, Stewart JP, Nash AA: Characterization of tumor cell lines derived from murine gammaherpesvirus-68-infected mice. J Virol 1996;70:6516-6518.

-5 Barton E, Mandal P, Speck SH: Pathogenesis and host control of gammaherpesviruses: lessons from the mouse. Annu Rev Immunol 2011;9:351-397.

-6 Virgin HW: Immune regulation of viral infection and vice versa. Immunol Res 2005;32 293-315.
Boyd AL, Orme TW: Transformation of mouse cells after infection with ultraviolet irradiation-inactivated herpes simplex virus type 2. Int J Cancer 1975;16:526-538.

8 Duff R, Rapp F: Oncogenic transformation of hamster embryo cells after exposure to inactivated herpes simplex virus type 1 . J Virol 1973;12:209-211.

-9 Kucera LS, Gudson JP, Edwards I, Herbst G: Oncogenic transformation of rat embryo fibroblasts with photoinactivated herpes simplex virus: rapid cloning of transformed cells. J Gen Virol 1977;35:473-485.

10 Takahashi M, Yamanishi K: Transformation of hamster embryo and human embryo cells by temperature sensitive mutants of herpes simplex virus type 2. Virology 1974;61:306311.

11 Weck KE, Kim SS, Virgin HW, Speck SH: B cells regulate murine gammaherpesvirus 68 latency. J Virol 1999;73:4651-4661.

-12 Rašlová H, Berebbi M, Rajčáni J, Sarasin A, Matis J, Kúdelová M: Susceptibility of mouse mammary glands to murine gammaherpesvirus 72 (MHV-72) infection: evidence of MHV-72 transmission via breast milk. Microb Pathogen 2001;31:47-58.
13 Ficová $\mathrm{M}$, Betáková $\mathrm{T}$, Pančík $\mathrm{P}$, Václav $\mathrm{R}$, Prokop P, Halásová Z, Kúdelová M: Molecular detection of murine herpesvirus 68 in ticks feeding on free-living reptiles. Microb Ecol 2011;62:862-867.

14 Etienne-Manneville S: Actin and microtubules in cell motility: which one is control? Traffic 2004;5:470-477.

15 Pawlak G, Helfman DM: Cytoskeletal changes in cell transformation and tumorigenesis. Curr Opin Genet Dev 2001;11:4147.

16 Royer-Pokora B, Beng H, Claviez M Winkhard HJ, Friis RR, Graf T: Transformation parameters in chicken fibroblasts transformed by AEV and MC29 avian leucemic viruses. Cell 1978;13:751-760.

17 Shutova MS, Alexandrova AY: Normal and transformed fibroblast spreading: role of microfilament polymerization and actin-myosin contractility. Cell Tissue Biol 2010;4:2535 . 